\title{
Coronary angioplasty in unstable angina and stable angina: a comparison of success and complications
}

\author{
R A PERRY, A SETH, A HUNT, M F SHIU \\ From the University Department of Cardiovascular Medicine, Queen Elizabeth Hospital, Edgbaston, \\ Birmingham
}

SUMMARY One hundred and five patients with unstable angina and 175 with chronic stable angina were treated by primary percutaneous transluminal coronary angioplasty. Patients with unstable angina had had symptoms for a shorter time and were more likely to have angiographically complex lesions and lesions $<10 \mathrm{~mm}$ in length than patients with chronic stable angina. Other baseline variables were not significantly different in the two groups. The overall primary success rate was similar in both groups $(87 \% v 86 \%)$. Nine of the 14 unsuccessful procedures in those with unstable angina and nine of the 24 unsuccessful procedures in those with stable angina were the result of acute occlusion. These results led to a $9 \%$ frequency of procedure related myocardial infarction in patients with unstable angina and a 5\% rate in those with stable angina (NS). The procedure related infarct rate tended to be higher in patients with unstable angina who had coronary angioplasty soon after an episode of unstable angina (mean 10 days) than in those in whom it was delayed (mean 35 days) (12\% v 3\%) (NS). In patients with unstable angina who had had a previous myocardial infarction procedure related infarction was significantly more common (18\%) than in patients with no previous myocardial infarction (3\%). The difference between those with and without previous infarction was also significant in patients with stable angina $(10 \% v 3 \%)$.

The term unstable angina has been used to describe a wide range of chest pain syndromes in differing clinical contexts. Other terms that have been used include acute coronary insufficiency, pre-infarction syndrome, crescendo angina, and post-infarction unstable angina. Unstable angina is defined as ischaemic chest pain, either at rest or on minimal exertion, lasting longer than 15 minutes with no evidence of infarction. The condition was associated with a high mortality in the 'first year after the unstable event-ranging from $10 \%$ to $40 \%$ depending on the particular subgroup studied. ${ }^{1-4}$ In most of these studies patients were on vigorous medical treatment. Only aspirin has been shown conclusively to be effective; it reduced the rate of myocardial infarction and the mortality by about half. ${ }^{5}$ While coronary artery bypass grafting has been shown to improve functional class and symptoms in patients with unstable angina, randomised studies have shown no overall improvement in mortality or myocardial infarction in surgically treated patients

Requests for reprints to Dr R A Perry, Cardiology Department, Queen Elizabeth Hospital, Edgbaston, Birmingham B15 2TH.

Accepted for publication 28 June 1988 compared with medically treated patients, ${ }^{67}$ and the surgical mortality in these patients is high.

Since the advent of coronary angioplasty ten years ago, the scope of the technique has been broadened to include various subgroups of patients with unstable angina of varying severity. ${ }^{8-11}$ The primary success rate is high, but acute major complications seem to be more common in patients with unstable symptoms than in those without.

We have examined the reasons for failure in our series of patients undergoing primary percutaneous transluminal angioplasty for clinically severe unstable angina and we compared the results with those in patients having the procedure for chronic stable symptoms. The procedure may fail because the target lesion cannot be crossed or because of vessel occlusion despite an initial uneventful dilatation. We also discuss the frequency and sequelae of acute occlusion in the two groups of patients in the light of our current understanding of unstable and stable angina.

\section{Patients and methods}

PATIENTS

There were 300 coronary angioplasty procedures at 
Table 1 Baseline characteristics and angiographic details in patients with unstable angina and stable angina

\begin{tabular}{lccc}
\hline & Unstable & Stable & Total \\
\hline No (\%) & $105(35)$ & $175(65)$ & $280(100)$ \\
M:F & $3: 1$ & $4: 1$ & $3.7: 1$ \\
Mean age (yr) & 47 & 52 & 50 \\
Mean duration & $8^{\star}$ & $27^{\star}$ & 19 \\
Target vessel: & & & \\
LAD (n (\%)) & $62(59)$ & $98(56)$ & $160(57)$ \\
RCA (n (\%)) & $29(28)$ & $55(31)$ & $84(30)$ \\
Cx (n (\%)) & $11(10)$ & $19(12)$ & $30(11)$ \\
Graft (n (\%)) & $3(3)$ & $3(1)$ & $6(2)$ \\
Multivessel (n (\%) & $13(12)$ & $13(7)$ & $26(9)$ \\
Unattempted & & & \\
occlusion & $4(4)$ & $15(9)$ & $19(7)$ \\
Characteristics of stenosis: & & & \\
Percentage narrowing & & & \\
$\quad$ (mean (SD)) & $70(10)$ & $76(8)$ & $74(9)$ \\
Concentric (n (\%)) & $85(72)$ & $124(66)$ & $209(68)$ \\
Eccentric (n (\%)) & $33(28)$ & $64(34)$ & $97(32)$ \\
$<10$ mm long & $85(72)$ & $86(46)$ & $171(56)$ \\
>10 mm long & $33(28)^{\star}$ & $102(54) \star$ & $135(44)$ \\
Complex (n (\%)) & $39(33)^{\star}$ & $30(16) \star$ & $69(23)$ \\
Occluded (n (\%)) & $4(4)$ & $10(6)$ & $14(5)$ \\
\hline
\end{tabular}

${ }^{*} \mathrm{p}<0.001$.

LAD, left anterior descending; RCA, right coronary artery; $\mathrm{Cx}$, circumflex.

the Queen Elizabeth centre between May 1983 and May 1987. Two hundred and eighty were primary procedures and all of them were performed by one of two principal operators. In 105 of the primary procedures the patients were classed as having unstable angina. All 105 had ischaemic chest pain at rest that lasted for $>15$ minutes and led to their admission to hospital, with or without ST/T wave changes on the electrocardiogram but with no new $Q$ wave formation, and without a diagnostic rise in cardiac enzymes. All the patients were admitted first to a coronary care unit with a suspected diagnosis of acute myocardial infarction. All received multiple antianginal medications because they continued to have chest pain at rest or on minimal exertion. Most (69) had recurrent chest pain requiring intravenous nitrates, and they could not be mobilised or discharged home before investigation and further intervention. The remainder (36) improved initially on medical treatment and they had coronary angiography and subsequently coronary angioplasty if they continued to have symptoms after they were mobilised.

Of those with unstable angina, 46 had a history of angina of less than one month or the episode of unstable pain was the first manifestation of ischaemic heart disease. Thirty eight $(36 \%)$ of those with unstable angina had already had a myocardial infarction. Most of these (30) had sustained their infarct at least three months before the episode of unstable angina. In six patients the myocardial infarct occurred within one month but not less than one week before their angioplasty. Twenty two $(21 \%)$ had had a $Q$ wave infarction and $16(15 \%)$ a non-Q wave infarction.

The remaining 175 patients had chronic stable angina. Of these, $63(36 \%)$ had had a previous myocardial infarction at least three months before the procedure $-45(26 \%)$ with $Q$ wave infarct and 18 $(10 \%)$ non-Q wave. All these patients had severe chronic stable angina on effort despite antianginal medications. Most $82(81 \%)$ of the total of 101 patients with previous infarction had angioplasty to the infarct related vessel-34 $(90 \%)$ of the 38 with unstable angina and $48(76 \%)$ of the 63 with stable angina. The remainder had angioplasty to a noninfarct related vessel.

Table 1 shows the baseline patient characteristics in the two groups. There were no significant differences in mean age, ratio of men to women, or target vessel between the two groups, although the proportion of diseased left anterior descending arteries was higher in patients with unstable angina. The duration of anginal symptoms was significantly shorter in those with unstable angina (8 $v 27$ months; $\chi^{2}=$ 11.15 , p $<0.001$ ). Four patients with unstable angina and 15 with stable angina had occluded arteries that were not the primary target vessel and were not attempted. These were patients with previous infarction who had angioplasty of a noninfarct related vessel as discussed above. Fourteen patients had occluded target vessels: four with unstable angina and 10 with stable angina. Eleven of these 14, two with unstable angina and nine with stable angina, had had a previous infarct.

The stenosis of the target vessel was assessed in two orthogonal planes and characterised according to its length ( $<$ or $\geqslant 10 \mathrm{~mm}$ ) and shape-concentric, eccentric, complex, or occluded. Length was assessed in the projection showing the longest aspect of the lesion. An eccentric stenosis was defined as one in which the lumen lay within one half of the putative normal lumen in at least one projection. A lesion was called complex if there was evidence of intraluminal clot, irregularity of the borders, or if it occurred on a bend of $>45^{\circ}$. The severity of stenoses and the ratio of concentric to eccentric lesions were similar in both groups. In patients with unstable angina there were significantly more complex lesions ( $33 v 16 \% ; \chi^{2}=$ $12.95, \mathrm{p}<0.001)$. There were significantly more lesions $>10 \mathrm{~mm}$ in length in those with stable angina (54v 28\%; $\chi^{2}=11.15, \mathrm{p}<0.001$ ). Twenty six patients ( 13 in each group) had a second vessel dilated as well as the primary target vessel and the characteristics of stenosis apply to all attempted vessels. 


\section{CORONARY ANGIOPLASTY}

Angioplasty was performed via the transfemoral route in all but two patients and a steerable balloon catheter system was used in all except the first 20 patients. All patients were treated with nifedipine (10 $\mathrm{mg}$ three times a day), isosorbide dinitrate (10 $\mathrm{mg}$ three times a day), and aspirin (300 $\mathrm{mg}$ daily) for at least $\mathbf{4 8}$ hours before the procedure if they were not already established on such treatment. During the procedure patients were heparinised and maintained on an infusion of isosorbide dinitrate. In patients with stable angina heparin was stopped after angioplasty, but in those with unstable angina it was continued as an infusion for 24 hours. Balloon inflation times and pressures varied with clinical circumstances, the angiographic result, and the improvement in transstenotic pressure gradient. In all patients in whom acute coronary occlusion occurred repeat angioplasty was immediately attempted. If this was unsuccessful patients were considered for emergency coronary artery bypass grafting.

A successful procedure was defined as a reduction in stenosis to $<50 \%$ of the diameter of the nearest normal vessel segment in the absence of a major complication-that is, procedure related myocardial infarction, coronary artery bypass grafting, or death.

We used the Minitab statistics package (Minitab Inc, State College, PA 16801, USA) for statistical analysis. Differences between the groups and in baseline data were compared by $\chi^{2}$ testing and unpaired Student's $t$ testing as appropriate.

\section{Results}

\section{SUCCESS RATE}

The overall primary success rate was similar in both groups (unstable angina 87\%; stable angina $86 \%$ ). Over the four year period of the study the success rate of the entire series improved from $80 \%$ to $92 \%$ (table 2) but there was no significant difference in success rate between patients with unstable angina and those with stable angina in any year. The proportion of patients with unstable angina increased significantly from $20 \%$ in $1983 / 84$ to $43 \%$ in $1986 / 87\left(\chi^{2}=8 \cdot 36\right.$, $p$ $<0.01$ ).
Table 3 Success rates, reasons for failure, and final outcome in the two groups

\begin{tabular}{lcc}
\hline & Unstable & Stable \\
\hline No (\%) & $105(35)$ & $175(65)$ \\
Success (n (\%)) & $91(87)$ & $151(86)$ \\
Failure (n (\%)) & $14(13)$ & $24(14)$ \\
Reason for failure: & & \\
$\quad$ Occlusion (n (\%)) & $9(9)$ & $12(7)$ \\
$\quad$ Failure to cross (n (\%)) & $5(4)$ & $12(7)$ \\
Final outcome & & \\
$\quad$ MI (n (\%)) & $9(9)$ & $9(5)$ \\
Death & 2 & 1 \\
CABG & 4 & 4 \\
\hline
\end{tabular}

MI, myocardial infarction; CABG, coronary artery bypass grafting.

\section{REASONS FOR FAILURE}

Table 3 shows the overall success rate and reasons for failure. A greater proportion of failures in those with unstable angina were caused by acute occlusion rather than failure to cross the stenosis (9\% v 4\%) whereas the same proportion of failures were caused by these two factors $(7 \% v 7 \%)$. In all patients with unstable angina the outcome of acute occlusion was an acute procedure related myocardial infarction, despite attempts at immediate re-angioplasty or referral for emergency operation. These results led to a $9 \%$ frequency of acute infarction in patients with unstable angina compared with $5 \%$ in those with stable angina. Two of the three deaths in the series were in patients with unstable angina. Four patients in each group had emergency coronary artery bypass grafting.

\section{TIMING OF INTERVENTION}

Sixty nine $(68 \%)$ of the patients with unstable angina had early coronary angioplasty at a mean interval of 10 days after the episode of unstable angina because despite intensive medical treatment they had continuing rest pain or severe angina limiting mobilisation. The remaining 36 (32\%) were mobilised on medical treatment and had coronary angioplasty at a mean interval of 35 days after the episode (table 4). The success rates in these two subgroups of patients with unstable angina were similar $(87 \% v 84 \%)$. Nearly all the failures in those who had early treatment were caused by acute occlusion. Only one patient who was

Table 2 Increase in proportion of patients with unstable angina and annual success rate in both groups throughout the series

\begin{tabular}{|c|c|c|c|c|c|c|c|c|}
\hline & \multicolumn{2}{|l|}{$1983 / 84$} & \multicolumn{2}{|l|}{$1984 / 85$} & \multicolumn{2}{|l|}{$1985 / 86$} & \multicolumn{2}{|l|}{$1986 / 87$} \\
\hline & Unstable & Stable & Unstable & Stable & Unstable & Stable & Unstable & Stable \\
\hline $\begin{array}{l}\text { Success }(\mathbf{n}(\%)) \\
\text { Failure }(\mathbf{n}(\%)) \\
\text { Total }(\mathbf{n}(\%)) \\
\text { Success rate }(\%) \\
\text { Overall success }(\%)\end{array}$ & $\begin{array}{c}9(82) \\
2(18) \\
11(20) \\
82 \quad \frac{}{} \quad 80\end{array}$ & $\begin{array}{r}36(80) \\
9(20) \\
45(80) \\
80\end{array}$ & $\begin{array}{l}12(80) \\
3(20) \\
15(28) \\
80 \quad 79\end{array}$ & $\begin{array}{l}30(79) \\
8(21) \\
38(72) \\
79\end{array}$ & $\begin{array}{l}33(87) \\
5(13) \\
38(51) \\
87 \quad 89\end{array}$ & $\begin{array}{c}34(92) \\
3(8) \\
37(49) \\
92\end{array}$ & $\begin{array}{l}37(90) \\
4(10) \\
41(43)^{\star} \\
90 \quad 92\end{array}$ & $\begin{array}{l}51(93) \\
4(7) \\
55(57)^{\star} \\
93\end{array}$ \\
\hline
\end{tabular}

$\star_{\mathrm{p}}<0.01$. 
Table 4 Success and reasons for failure in patients with unstable angina that was treated early and late after the unstable event

\begin{tabular}{lll}
\hline & $\begin{array}{l}\text { Early } \\
(10 \text { days })\end{array}$ & $\begin{array}{l}\text { Late } \\
\text { (35 days) }\end{array}$ \\
\hline No (\%) & $69(66)$ & $36(34)$ \\
Success (n (\%)) & $60(87)$ & $31(86)$ \\
Failure (n (\%)) & $9(13)$ & $5(14)$ \\
$\begin{array}{l}\text { Reason for failure } \\
\text { Occlusion (MI) (n (\%)) }\end{array}$ & $8(12)$ & $1(3)$ \\
Failure to cross (n (\%)) & $1(1)$ & $4(11)$ \\
\hline
\end{tabular}

MI, myocardial infarction.

treated later had acute occlusion; the predominant cause of failure in this group was difficulty in crossing the lesion. The numbers are small and the differences are not statistically significant.

\section{PREVIOUS MYOCARDIAL INFARCTION}

Table 5 shows the relation of previous myocardial infarction to success in the groups with unstable or stable angina. The proportions of patients with unstable angina and with stable angina who had had a previous myocardial infarction were the same $(36 \%)$. In both groups the rate of procedure related myocardial infarction was significantly higher in patients with previous myocardial infarction: $18 v 3 \%\left(\chi^{2}=\right.$ $7.49 ; \mathrm{p}<0.01)$ in unstable angina and $10 v 3 \%\left(\chi^{2}=\right.$ $3.91 ; \mathrm{p}<0.05)$ in chronic stable angina. There was no significant difference between the groups with unstable and stable angina with previous myocardial infarction.

\section{Discussion}

We retrospectively reviewed our series of patients who had coronary angioplasty and we specifically examined the success rate and reasons for failure in patients with unstable angina and compared them with those in patients with chronic stable angina. The overall success rate was similar in both groups of

Table 5 The influence of previous myocardial infarction on success and failure of angioplasty in both groups

\begin{tabular}{|c|c|c|c|c|}
\hline & \multicolumn{2}{|c|}{ Unstable (105) } & \multicolumn{2}{|c|}{ Stable (175) } \\
\hline & $\begin{array}{l}\text { Previous } \\
\text { MI }\end{array}$ & $\begin{array}{l}\text { No } \\
\text { previous MI }\end{array}$ & $\begin{array}{l}\text { Previous } \\
\text { MI }\end{array}$ & $\begin{array}{l}\text { No } \\
\text { previous MI }\end{array}$ \\
\hline $\begin{array}{l}\text { No (\%) } \\
\text { Success (n (\%)) } \\
\text { Failure (n (\%)) }\end{array}$ & $\begin{array}{l}38(36) \\
29(76) \\
9(24)^{\star}\end{array}$ & $\begin{array}{l}67(64) \\
62(92) \\
5(8)^{\star}\end{array}$ & $\begin{array}{l}63(36) \\
49(78) \\
14(22) \dagger\end{array}$ & $\begin{array}{r}112(64) \\
102(91) \\
10(9) \dagger\end{array}$ \\
\hline $\begin{array}{l}\text { Reason for failure: } \\
\text { Acute occlusion } \\
\text { (MI) (n (\%)) } \\
\text { Failure to cross }\end{array}$ & $\begin{array}{l}7(18) \\
2(6)\end{array}$ & $\begin{array}{l}2(3) \\
3(5)\end{array}$ & $\begin{array}{l}6(10) \\
8(12)\end{array}$ & $\begin{array}{l}3(3) \\
7(6)\end{array}$ \\
\hline
\end{tabular}

${ }^{\star} \mathrm{p}<0.01 ; \mathrm{tp}<0.05$.

MI, myocardial infarction. patients, but in patients with unstable angina failure was more likely to be caused by acute occlusion and consequent procedure related myocardial infarction rather than failure to cross the lesion. Patients with unstable angina who needed urgent treatment for continuing symptoms seemed to have a higher rate of acute occlusion than patients whose symptoms were controlled by medical treatment. Patients in both angina groups who had sustained a previous myocardial infarction had a significantly lower success rate and a higher frequency of acute occlusion; the resulting rates of procedure related infarction were $18 \%$ in patients with unstable angina and $10 \%$ in those with stable angina.

Patients with unstable angina form a heterogeneous group containing those with recent onset angina (presenting as a first ischaemic event), patients with pre-existing exertional angina that has become unstable, and patients who have sustained a previous myocardial infarction. None the less, we believe that our patients presented with a relatively uniform clinical problem. Whatever the preceding history, whether it was recent onset angina, previously chronic stable angina, or previous myocardial infarction, all these patients presented with an episode of rest pain thought initially to be caused by myocardial infarction; hence their admission to a coronary care unit. Because patients in these different subgroups may have a different prognosis if they remain untreated we have examined the results of angioplasty according to subgroup. Most patients required early intervention because intensive medical treatment failed to control their symptoms. Even patients in whom medical treatment, including aspirin, controls their symptoms have an event rate of up to $12 \%{ }^{12}$ if they remain on medical treatment.

The patients discussed here are pre-selected groups in that their coronary artery structure was regarded as being suitable for angioplasty. This explains the low rate of occlusion in target vessels in 101 patients who had already had an infarction. We did not attempt 19 occlusions and some of these patients had had non- $Q$ wave infarcts. Their subsequent clinical course indicates that most of the patients with unstable angina were at increased risk; the event rate in the subsequent year was $40 \%$.

Any analysis of a series of patients treated by coronary angioplasty must take into account the influence of improving operator experience and any changes in practice during the study period. Table 2 shows that the overall success rate improved over the four year period as the experience of the operators increased and equipment improved. The success rates in the two subgroups with unstable and stable angina remained similar throughout the period, even though the proportion of patients with unstable 
angina increased $(20 \%$ in $1983 / 84$ and $43 \%$ in $1986 /$ 87) after it was recognised that coronary angioplasty is successful in many patients with unstable angina.

Although the overall success rate was high in patients with unstable angina, procedure related myocardial infarction was more common than in patients with chronic stable angina, especially in patients with severe disease-that is, those who were treated early. The suggested mechanism for the development of unstable angina is rupture of an atheromatous plaque with subsequent platelet aggregation and thrombosis, and possibly superimposed coronary spasm. ${ }^{1314}$ Analysis of the coronary arteriograms of our patients showed that patients with unstable angina had a significantly higher proportion of complex lesions ( $33 v 16 \% ; \chi^{2}=10 \cdot 72$, $p<0.001)$. We believe this is likely to have contributed to the higher rate of acute occlusion within the group with unstable angina. There was no direct correlation between patients with abnormal arteriograms and failed procedures, but these numbers are small. We assessed the complexity of lesions by the method used by Ischinger et al, who suggested that a complex angiographic lesion may be a risk factor for dissection or acute occlusion, though the predictive value of this index was low. ${ }^{15}$ The presence of intraluminal thrombus on angiography may depend on the timing of the angiogram in relation to an episode of unstable angina because a longer interval will give more opportunity for resolution of the thrombus. There is no satisfactory explanation for the higher rate of acute occlusion when there is angiographic evidence of intraluminal thrombus. The thrombus itself is rarely evident after angioplasty either in the lesion itself or in the vessel beyond. It could be that the recently ruptured plaque predisposes the vessel to extensive dissection with the associated risk of vessel occlusion. The only other significant difference in coronary artery structure is that patients with stable angina had longer stenoses (54 v $28 \%>10 \mathrm{~mm}$ ). This may explain why failure was the result of difficulty crossing the lesions in a higher proportion of patients with stable angina. ${ }^{16}$

The failure rate owing to acute occlusion was significantly higher in all patients (both groups) who had had a previous myocardial infarction, as we have reported before. ${ }^{17}$ It is possible that as well as an underlying susceptibility to plaque rupture these patients also have a poorly developed collateral circulation in the areas surrounding the infarcted zone.

The overall frequency of acute occlusion and consequent procedure related myocardial infarction in our study seems to be slightly higher than in other series of percutaneous transluminal coronary angioplasty in unstable angina, ${ }^{918}$ though it resembles that reported by the National Heart, Lung and Blood Institute registry. ${ }^{19}$ In the absence of previous infarction or in patients treated later after their episode of unstable angina the procedure related infarction rate is low and similar to that in patients undergoing angioplasty for chronic stable symptoms. As discussed above, we believe many of our patients were at high risk and that early intervention was unavoidable in most.

The overall $9 \%$ procedure related myocardial infarction rate for angioplasty in patients with unstable angina should be viewed in the light of the known high subsequent infarction rate on medical treatment. It is clear that some subgroups have a higher risk of infarction at angioplasty than others and it is one of the aims of this paper to try to identify some of the relevant risk factors. It may be that the group with the highest complication rate $(18 \%)$ should have been treated by coronary artery bypass grafting, but published data show that mortality at operation is $5 \%$ compared with $2 \%$ at angioplasty, and there are few data on the frequency of perioperative infarction. Ideally, a randomised study based on intention to treat should be carried out to compare percutaneous transluminal coronary angioplasty with medical and surgical treatment and to explore both the short and long term benefits of the procedure. In our study clinical follow up of patients with unstable angina (1-3 years, mean 16 months) shows that only one of the patients in whom angioplasty was successful has had a myocardial infarction and there have been no late deaths. Our results support reports from other centres that coronary angioplasty is an appropriate treatment in selected patients with unstable angina.

In conclusion, it seems that various subgroups of patients with unstable angina can be successfully treated by coronary angioplasty. In this series acute procedure related myocardial infarction was more common in patients with unstable angina than in patients with stable angina. This was because patients with unstable angina had more severe symptoms that required early intervention. We believe that this reflects the unstable nature of a recently ruptured plaque with a raw thrombogenic surface. While coronary angioplasty is a useful option and has a high overall success rate in patients with unstable angina, careful risk analysis should be undertaken for all patients.

Dr R A Perry is supported by the British Heart Foundation.

\section{References}

1 Mulcahy R, Daly L, Graham I, et al. Unstable angina: natural history and determinants of prognosis. $\mathrm{Am} \mathrm{J}$ 
Cardiol 1981;48:525-31.

2 Gazes PC, Mobley EM Jr, Faris HM Jr, et al. Preinfarction (unstable) angina, a prospective study: ten year follow up. Circulation 1973;48:331-8.

3 Olson HG, Lyon KP, Aronow WS, et al. The high risk angina patient: identification by clinical features, hospital course, electrocardiography and technetium$99 \mathrm{~m}$ pyrophosphate scintigraphy. Circulation 1987; 64:674-80.

4 Harris RJ, Harrell PE, Kee KL, et al. Survival in medically treated coronary artery disease. Circulation 1979;60:1259-65.

5 Lewis HD Jr, Davis JW, Archibald DE, et al. Protection effect of aspirin against acute myocardial infarction and death in men with unstable angina: results of a Veterans Adminstration cooperative study. $N$ Engl $J$ Med 1983;309:396-401.

6 Conti CR, Hodges M, Hutter A, et al. Unstable angina-a National Cooperative study comparing medical and surgical therapy. Cardiovasc Clin 1977;8:167-78.

7 Selden R, Neill WR, Riteman LW, et al. Medical versus surgical therapy for acute coronary insufficiency. A randomised study. N Engl J Med 1975;293:1329-37.

8 Faxon D, Detre K, McCabe C, et al. Role of percutancous transluminal coronary angioplasty in the treatment of unstable angina. Report from the NHLBI percutaneous transluminal coronary angioplasty and coronary artery surgery study registries. Am J Cardiol 1983;53:13K-5C.

9 De Feyter PJ, Serruys PW, Arnold A, et al. Coronary angioplasty of the unstable angina related vessel in patients with multivessel disease. Eur Heart $J$ 1986;74:460-4.

10 De Feyter PJ, Serruys PW, Jouard A, et al. Coronary angioplasty for early post infarction unstable angina.
Circulation 1986;74:1365-9.

11 Steffenino G, Meier B, Finci L, Rutishauser W. Follow up results of treatment of unstable angina by coronary angioplasty. Br Heart J 1987;57:416-9.

12 Cairns JA, Gent $M$, Singer J, et al. Aspirin, sulphinpyrazone, or both in unstable angina. $N$ Engl $J$ Med 1985;313:1369-75.

13 Willerson JI, Campbell WB, Winniford MP, et al. Conversion from chronic to acute coronary artery disease: speculation regarding mechanisms. Am J Cardiol 1984;54:1349-58.

14 Davies MJ, Thomas AC. Plaque fissuring - the cause of acute myocardial infarction, sudden ischaemic death, and crescendo angina. Br Heart J 1985;53:363-73.

15 Ischinger T, Gruentzig AR, Meier B, Galan K. Coronary dissection on total coronary occlusion associated with percutaneous transluminal coronary angioplasty; significance of initial angiographic morphology of coronary stenoses. Circulation 1986; 74:1371-5.

16 Meier B, Gruentzig AR, Hollman J, et al. Does length or eccentricity of coronary stenoses influence the outcome of transluminal dilatation? Circulation 1983;67:497-501.

17 Perry RA, Singh A, Seth A, Shiu MF. Success and complication rates of coronary angioplasty in patients with and without previous myocardial infarction. Eur Heart J 1988;9:37-42.

18 De Feyter PJ, Serruys PW, Van den Brand M, et al. Emergency coronary angioplasty in refactory unstable angina. N Engl J Med 1985;313:342-9.

19 Dorros G, Cowley MJ, Simpson J, et al. Percutaneous transluminal coronary angioplasty: report of complications from the National Heart, Lung and Blood Institute. PTCA registry. Circulation 1983;67: 723-33. 